\title{
Teaching in Diversity: Managing "Differences" in a Multicultural Classroom
}

\author{
Zheng Zhu \\ New York City College of Technology \\ New York City, The United States
}

\begin{abstract}
Numerous studies have paid attention to the presence of diverse cultural voices in a multicultural educational setting. This article continues this important conversation by focusing on how the different voices meet and negotiate with each other in a classroom where diversity exists, and yet is not equally represented. Thus, finding a solution that can respect and manage the different cultural norms and practices is vital to the success of the class and students. Grounded on the theoretical foundation of discourse analysis, this study was conducted through interviewing the course instructors, students, and observing their classes. The analysis shows that developing a mutually inclusive cross-cultural dialogue among students can lead to the positive integration of the distinct cultural perspectives. Ultimately, a productive and respectful teaching and learning environment will be fostered and sustained.
\end{abstract}

Keywords: diversity; culture; teaching; learning; interaction.

\section{Introduction}

When I studied the relationship between cultural values and communication behaviors, I found the key point of decoding this relationship was not to discover which one determines the other, but to clearly understand how they influence each other in a multicultural environment. Thus, I need to find a situation where people holding different cultural values interact. It is through observing these interactions, I would be able to see how the different cultural values emerge, negotiate, and even struggle. I set two goals for this study; the 
first one is to develop an in-depth observation and analysis of the conflicting cultural perspectives. The second goal is to identify a specific method to effectively balance and manage the cultural differences. I picked a multicultural classroom as the research location, where students from various countries and regions actively interacted with each other. In particular, when it comes to class rules and norms, the arguments surrounding what is right or wrong, appropriate or inappropriate are quickly brought to the table due to the presence of the competing cultural values.

\section{Literature Review}

Begley and Stefkovich (2004) argued that the administrators managed schools through a fairly limited repertoire of managerial processes. "There was seldom much need to reflect on the suitability of the established practices as guides to action. Management was largely a function of the comfortable, well-worn, and proven procedures" (Begley \& Stefkovich, 2004, p. 133). School was traditionally an arena for professional activity and considered a holy place where equity, diversity, and creativity are nurtured and protected (Begley \& Stefkovich, 2004).

However, such ideal construction of education system is often challenged by the existing social circumstances (Begley \& Stefkovich, 2004). For example, Gutierrez and Preston (2004) explored the important ethical issues for universities that were using race as a consideration in their admission decisions. A discussion of several important United States Supreme Court cases was provided as well as an analysis of these decisions using an ethical framework that incorporated five key perspectives: ethic of critique, ethic of justice, ethic of profession, ethic of race, and ethic of community (Gutierrez \& Preston, 2004).

Both Barlatt (2000) and Ketko (2017) explored the ethical dilemmas in the current higher education system. They noticed that the students' academic performances closely depend on the caring attitude of the instructor, as well as, the type and frequency of the student - teacher interactions (Barlatt, 2000; Ketko, 2017). Barlatt recognized that the ethical issues in higher education have been ignored for a long time, and there were very few empirical studies focused on higher education ethics (Barlatt, 2000). Furthermore, most teachers started their careers with little knowledge of the ethical dilemmas that occurred in the classroom (Barlatt, 2000).

Jonsson (2001) argued that, "a growing number of school districts are warming to the idea of ethics classes." Jonsson questioned the ethical awareness of the teachers and he encouraged the school authority to examine the teachers' ethical reliability. He thought teachers educate students to be ethical and responsible. Therefore, it is very important to make sure that the teachers are the responsible 
and moral adults in the first place (Jonsson, 2001).

Nevertheless, Jonsson defended the teachers' position by making the claim that the students nowadays tend to be more provocative and sophisticated. The problem is rooted in the fact that the current generation of our teaching team never learned the basic rights and wrongs (Jonsson, 2001). Jonsson's view is very clear that we need to raise our teachers' ethical awareness in teaching and mentoring. However, when an ethical problem occurs in a school setting, we should not blame it only on the part of the teachers (Jonsson, 2001). We need to examine the issue from multiple social and cultural perspectives because students also assume the responsibilities in certain cases (Jonsson, 2001). On the other hand, Jonsson realized that the society has been changing in a fast pace, so has the people's definition of morality. The young teachers may not learn ethics the way their parents' generation was taught (Jonsson, 2001). Therefore, not only the society, but also the ways people define ethics have changed based on the social and cultural values that people held across different historical stages (Jonsson, 2001).

Murphy (2005) studied the leadership capability of teachers in a multicultural setting. He examined if the leadership aptitude could be an important factor influencing the class disciplines and the students' academic performances (Murphy, 2005). In his research, Murphy argued that the leadership aptitude is essential to keeping a culturally diverse classroom under control, especially for a teacher who does not speak the local language as his or her first language. Murphy (2005) analyzed the ways foreign teachers handled the conflicts with domestic students in American colleges. He pointed out that the domestic students always held a certain language privilege and cultural prejudice when communicating with foreign faculty members. Such high sense of privilege and prejudice often made domestic students feel entitled to break the class rules, one of their common arguments for breaking the rules is those rules were inconsistent with American cultural values (Murphy, 2005). Hence, it is usually hard for a foreign teacher to receive recognition and respect from domestic students; even they have the knowledge, experience, and capacity (Murphy, 2005). These positive traits were easily overshadowed by the perceived and superficial cultural barriers such as foreign accent and non-American physical appearance (Murphy, 2005). At this part, Murphy argued that the leadership aptitude could sometimes downplay these barriers, and it usually includes the following aspects: 1) sense of humor, 2) intercultural flexibility, and 3) display of assertiveness.

Among these three aspects, intercultural flexibility is rated as the foremost quality (Murphy, 2005). Foreign teachers need to develop a strong cultural receptivity 
because they work with students of diverse cultural backgrounds (Murphy, 2005). How to maintain a decent level of fairness in a culturally diverse environment is the challenge here (Murphy, 2005). Especially when international students expected to be treated differently due to the cultural values they held and the following common assumptions: "we are not from here, so we should not be assessed as harsh as those who grew up here" (Murphy, 2005, p. 112). "My professor is foreign too, so he or she must understand us better than their domestic counterparts, therefore it should not be that hard to survive this teacher's class" (Murphy, 2005, p. 112). That is why foreign teachers usually have a difficult time searching for a universal law to manage the entire class well and fair because there was no such law that could be applied to every situation, or in other words, make everyone happy while maintaining his or her integrity as the professional academic (Murphy, 2005).

In response to such complex circumstance, some scholars and educators called for giving more authority and power to international faculty because they usually have a harder time to balance between the dominant and the other-ed cultural values. For example, domestic students often perceive international faculty members as incapable of teaching the class (Kim, Wendel \& Twombly, 2011). It is a daily struggle for the international faculty members to manage the cultural differences, as they constantly have to fight the prejudices of different levels and types (Kim, Wendel \& Twombly, 2011).

Alberts and Hazen (2010) examined factors that affect U.S. college students' perceptions of the domestic and international instructors' teaching effectiveness. A questionnaire including the measures of ethnocentrism, intercultural communication apprehension, willingness to communicate, and motivation was completed by 204 participating students (Alberts \& Hazen, 2010). Further, the students responded to affective, cognitive, and behavioral measures with regard to the domestic and international instructors' teaching effectiveness (Alberts \& Hazen, 2010). The result revealed that the students rated domestic instructors more positively than their international counterparts (Alberts \& Hazen, 2010). In addition, the findings indicated that the students with ethnocentric mentality tended to view domestic teachers more favorably than the international faculty (Alberts \& Hazen, 2010). Alberts and Hazen found that the students with higher levels of motivation toward learning were somewhat more willing to communicate with international teachers. The students with high levels of intercultural communication apprehension rated international teachers much more negatively than domestic teachers (Alberts \& Hazen, 2010).

The above findings have proven that it is more challenging for a foreign teacher to manage a class attended mostly by domestic students. But the changing 
landscape of U.S. college campus requires current scholars to re-think about these findings; the growing number of international students and students of different cultural groups have gained a stronger presence and impact in college classroom nationwide (Tompson \& Tompson, 2010). A class is usually full of students from many different countries and cultural backgrounds. They all have their own knowledge, perceptions, and viewpoints about what are considered appropriate and inappropriate behaviors in a classroom (Tompson \& Tompson, 2010). Therefore, it becomes increasingly important to study how a course instructor teaches and manages a multicultural higher education learning environment. Following this line of thinking, a key research question is identified: should the college course instructors set up a class discipline to treat every student the same way or do they need to identify diverse class rules for students of different cultural backgrounds?

\section{Method}

The following section specifies the theoretical model upon which I grounded my analysis and the methodology that I adopted for data collection.

\section{Discourse Analysis}

Qualitative scholars define discourse as a form of voice, language, representation, and sometimes even symbols that produce meanings (Gee, 2014). To understand the complexity of a particular type of discourse, we need to study the context and text where the discourse is created (Gee, 2014). Context refers to the historical, social, and cultural condition that affects the way a specific form of discourse is used by the creator and understood by the audience (Gee, 2014). Text means the material base where discourse is written, printed, or published (Gee, 2014). Text determines the nature, formality, and structure of the discourse (Gee, 2014).

For example, an article published in a newspaper about illegal immigration won't be the same as an article with the same theme published in a research journal because a news report or commentary is written in a different way than a scholarly article (Gee, 2014). The choice of words and structure of the arguments will be all different because newspaper and journal represent two different types of texts (Gee, 2014). Moreover, the same news article about illegal immigration in the United States will be read differently and receiving different reactions from people who come from different national, cultural, and religious groups (Gee, 2014). These national, cultural, and religious groups represent the contexts that produce the lenses that people use to understand the meanings conveyed by the article (Gee, 2014). Thus, as Gee (2014) pointed out, discourse analysis is an interpretative process through which a researcher discovers the meanings underlying the words, images, and representations, and how the meanings are created in the current sociocultural context. 
Grounded on Gee's theoretical model of discourse analysis, my research design and data analysis are focused on how the larger sociocultural contexts affect the domestic and international students' different understandings of appropriate inclass behaviors. I aim to find out how these understandings could be incorporated into the process of improving the existing teaching practices and reforming the current pedagogical structure in college education.

\section{Study Design}

I adopted two methods for this project: the first one was a series of semistructured interviews. The second one consisted of non-participation observations. My interviewees were domestic and international students and faculty members. The distributions for both the research participants and interview questions were very equal. For example, if I asked a certain question to five domestic students, then I asked the same question to five international students. I strived to ensure my data represented a culturally diverse population and showed a numerically representative sample for research purposes.

The institution where my IRB application was approved, and data collection took place was a Northwestern public land-grant university. I made, respectively, four non-participation observations in both international and domestic instructors' classes. I wanted to study and compare the ways students thought and behaved in domestic and international instructors' classes. Through conducting these non-participation observations, I intended to examine the key factors that led up to the participants' different understandings about teaching and in-class behaviors.

\section{Analysis}

As Rogoff (2003) pointed out, there were no cultural norms guiding all forms of human behaviors and the ways people think. Although there are no such universally-shared cultural norms and practices, people tend to conform to the common legal systems and practices (Liu, 2009; Uskul, Lalonde \& Cheng, 2007; Zhong, 2008). For example, robberies and murders are considered illegal acts and would receive penalties across all cultures and societies (Liu, 2009; Zhong, 2008). But when it comes to situations involving behaviors such as giving one's seat to the seniors or disabled on a bus or challenging your professors in a class, different explanations, interpretations, and arguments would emerge as a result of people's differing ways of perceiving these situations and behaviors because of their cultural backgrounds (Liu, 2009; Zhong, 2008).

The interviewed domestic students said that it is normal to express different opinions and form an argument against the authority. In their view, it is every 
student's right to voice their disagreements in response to professor's speech. Some domestic students directly stated, "this is a free country, we have freedom of speech, and you are entitled to speak your mind!" Such comment is in a sharp contrast to the statement provided by the international students.

One international student from China said, in Chinese culture, or Asian culture overall, it would be considered rude and disrespectful if a student kept asking tough questions that challenge the professor's authority as the expert on the subject. She still remembered when she was a college sophomore; a student asked a series of difficult questions concerning the philosophical interpretation of a Chinese poem that the professor was lecturing on. When that student was trying to give the third question, the professor became irritated and lost his temper, yelling at him: "who is the leader of this class, you or me? Who do you expect to teach this course? Do you want me to step down and let you take my seat?" She told me that she used to feel it was that student's mistake, who should not have questioned his professor in the middle of a class and in front of other students. She felt it was impolite to shoot out questions to your professor. She thought we need to treat our professors with the same respect we have for our superiors at workplaces and elders in the family.

Another international student from South Korea recalled that she was raised to be obedient and humble when talking to teachers because they have more knowledge than us on the subject. This cultural norm also spreads to the situation where she was taught to follow the advice and accept the criticisms from her parents, who are considered more knowledgeable and experienced because of their age and authoritative status in the familial relationship. Teaching professionals are traditionally worshipped as holding a position superior to the students because they are the leaders of the classes and would enlighten their students with important knowledge and great ideas (Moffat, 1995). In this sense, the educators assume the power of an employer in a professional organization and the pivotal role of parents in familial setting (Moffat, 1995). As this Korean international student said, people in her culture tend to think teachers are always selfless and they provide you with knowledge and skills crucial to your future success in life. Thus, it would be unwise and very unkind to challenge them.

Comparatively, I found that the domestic students talked to their instructors like they talked to their friends. They constantly used the words such as man, or the instructors' first names to address them. These students rarely called the instructors by their professional or academic titles such as Prof. or Dr. This is different from international students, who often addressed their teachers by the professional titles. An Italian student told me that in Italy, students would stand 
up when they see the teacher walking into the classroom. He also said every student should take off their hats and sit properly in the chairs. But he saw some students here laying their legs on the chairs. It looks like they were on a beach enjoying the sun. He felt that some domestic students did not respect International faculty because they did not speak English the American way, or in his words, their English sounds funny and clumsy. This Italian student's comment was echoed by an International faculty member from Spain, who told me that she noticed some domestic students laughing and giggling at the back of the classroom when she was giving the lecture. She figured that was due to her foreign accent and ways of expression, which might appear bizarre to the local students.

However, the domestic students told me that they behave the same way in every class, not just in foreign instructors' classes. They also claimed that it has nothing to do with culture or accent. It is the ways we college kids act in any other classes. Leonard (2006) called for a greater level of tolerance in a multicultural learning environment. This study introduced three essential qualities that a teacher should possess when working with diverse student groups. The first one is cultural consciousness, which centers on evaluating the students' in-class performances based on their specific cultural experiences and backgrounds (Leonard, 2006). The second one is intercultural sensitivity, which means instructors need to respect the cultural differences among students in a class (Leonard, 2006). The third quality is commitment to social justice, which, in a multicultural classroom setting, can be translated as finding a way to establish certain class rules that are fair to all (Leonard, 2006). But is it possible to create a set of course policies or rules to manage all the cultural differences? I am struggling with the possible outcome that some students would always feel their rights are violated or voices are marginalized.

One international faculty member told me he demanded all students take off their hats and put their legs off the chairs. He recalled all the domestic students who looked quite confused. It seemed that they did not understand the point of doing it. Although the students followed this requirement, some seemed unhappy when doing it and lots of them did it only after seeing others do it. Since then, he has waited to start every class after all the students took their hats off first. The class was quiet throughout the semester. He told me he felt very uncomfortable and sometimes even strange because a silence like this is not what he wanted for the class. He said in the past whenever he raised a question, students were very responsive. But now everyone stays quiet. He asked some of his students who used to speak a lot in class "why have you been so quiet lately?" They told him that they thought he was mad because his tone was serious when asking them not to wear hats and lay their legs on the chairs. The 
students did not know what to do and how to act. They were afraid of further upsetting him if they said something wrong or offensive. He immediately realized that the new class rule reinforced his authoritative position, and yet discouraged students from interacting and participating. He made it clear in the interview that he should've first asked why they wore the hats. Instead, he told them to quit doing it because he saw it as a sign of disrespect or not taking this class seriously. His students told him that wearing hats and putting feet on the chairs were common behaviors in college classes and they were not meant to disrespect the professors.

Next week in the same class, he made an announcement that all students must volunteer to speak up or answer his questions if they wanted to receive full credits for class participation. Pushed by this new rule, the domestic students became very active and competed to answer his questions one after another. That being said, what appeared confusing to him was that the international students remained silent even though he kept reminding them it was important to participate in class discussions for both learning the materials and receiving credits. The international students were quiet and not motivated to speak in class. But he could tell from the submitted assignments that these international students had many great thoughts. He felt it was possible that these international students were too nervous to speak out because their language barriers lowered their self-esteem, which made them think their voices would not have been taken seriously by others. When I asked him: "who are these others? He said others meant domestic students.

He told me that he asked some international students about why they did not actively participate. They said they preferred not to talk too loud. They did not want to be embarrassed or embarrassing others because English was their second language. They were concerned that the other students would be confused or in worst-case scenario, laughing, at them if they failed to make the point clear. The Asian students told him that they did not want to act arrogant by speaking too much and loud. They only felt comfortable speaking in front of others if the instructor asked them a question. Further, they told him that they considered talking too much or acting like you know a lot about the subject rude to the professor, who was supposed to be supreme leader of the class. In their opinion, students should focus on taking notes and answering questions. This conversation between the interviewed instructor and his students drove me to think about the following three questions; did this instructor violate the cultural norms of the domestic and international students? How should he manage such complicated situations involving cultural clashes? Did his cultural background play a part in affecting the ways the class was taught? 
At the end of our interview, he said he made an in-class apology the following week about his demands that students take the hats off and everyone speak up for receiving participation credits. He saw students smiling at him upon hearing the apologetic statement. The class went back to normal. Students acted comfortably and seemed happier. For example, they showed enthusiasm in class discussions. He sometimes raised a few questions directed to the international students, to ensure they were following the class. A couple of days later, he received several emails from the students, who expressed their gratitude to him and praised him as a caring person and excellent instructor. One of them stated: "I enjoyed this class so much. I am blessed to have a great professor like you. You did not need to apologize for anything."

Another international faculty member that I interviewed said she once organized a game in her public-speaking class. In this game, all the students were told to pass around a doll as she turned her back to them knocking on the blackboard. As soon as she stopped, the student who had the doll must give an impromptu speech for two minutes. This game was meant to let every student have fun and learn important lessons that can help them gain confidence and valuable public speaking experiences. However, after the class a Japanese student told her that this game scared her. The other Japanese students also complained to her that this game brought a high level of intensity, which made them feel uncertain, anxious, uptight, and very stressful.

She felt she was stuck in an ambivalent situation. She did not know if the game should be kept because of these conflicting voices; contrary to the international students' negative reactions, the domestic students really enjoyed the game. She said when she apologized to the students the next day about the game, some domestic students shook their heads and murmured: "no, it was actually really fun." Meanwhile, she took a notice of the facial expressions on international students; some of them were smiling at her, which sent the message that not only they accepted her apology, but they were also happy to see their voices were respected in a multicultural learning environment. She did not play this game in the following parts of the semester. Instead the students were organized into different groups to discuss the questions she raised. Her pedagogical approach intrigued me into thinking about these questions: "was it right to stop the game because the complaints of a few international students? What about the interests of domestic students? How could she, as a professor, balance between the two competing cultural perceptions?" She told me the domestic students looked confused about her apology and seemed very disappointed at her decision of discontinuing this fun and creative class activity. 
Reflecting at the way she handled the situation, she regretted about not being able to accommodate the needs of domestic students. She felt she made a hasty decision to only support the international students. Her reflection drove me to contemplate about the role that the faculty member's own cultural background and experience played in affecting her teaching philosophy and decision-making processes. She has a background as an international graduate student before working as a faculty member. It was easy for her to relate to the experiences and feelings of international students. So her decision of keeping or cancelling the game was driven by the needs of those she closely identify with, in a cultural sense. Comparatively, the voices of other students whom she felt distant to were easily ignored. Her explanation alludes to the critical understanding about the impact of faculty members' cultural identities; they need to be aware of the ways their own cultural perceptions and experiences shape their pedagogical approach (Cowley \& Hanna, 2005).

The next interviewed domestic faculty member told me that the only class activity she arranged was group discussion. She mixed domestic students with international students in various group projects as a way to improve mutual understandings and remove the cultural barriers. Nevertheless, the result was not satisfactory. The domestic and international students were not interested in interacting with each other. When I asked about the reason (s) behind it, she responded that the domestic students had problems understanding the international students' English. Further, they pointed out that international students usually viewed the discussion topics from their own cultural standpoints. It is hard to communicate with them because they did not think like us in the first place. Thus, the domestic students felt there was no common language, both culturally and linguistically, between each other.

The international students' responses were that they felt American students were hard to get along with, let alone befriend. They were self-centered, indifferent, and only interested in talking to their own people. She said that international students wanted to be accepted by American culture and society, but they also hoped to have their own opinions included. International students' desire of making their voices heard and respected is an indicative of the difficulty that the newcomers often experience when trying to reach the ideal of cultural integration in a multicultural communication environment (Ersanilli \& Koopmans, 2010). Their negative characterization of domestic students as cold and selfish Americans, and the domestic students' criticism over international students' English proficiency further uncovered the ways in which the crosscultural misunderstandings were created and exacerbated in a seemingly culturally-diverse setting where diversity was present, and yet not supported (Cowley \& Hanna, 2005; Martin \& Nakayama, 2010). 
It is natural for a foreign sojourner to feel both excited and lonely upon entering a new cultural environment (Martin \& Nakayama, 2010). For one thing, they yearn to become part of the local culture. For another, they fear the rejection (Martin \& Nakayama, 2010). International students were sensitive to the attitudes of domestic students. If they felt they were not welcomed, they would retreat to their own cultural groups and easily develop negative perceptions over the cultural values or practices embraced by the host cultural group.

Research examining the factors that contribute to the successful and failed acculturation of international students revealed that, the key factor leading to the successful acculturation of international students was the effective reduction of one's anxiety before or during the process of the cross-cultural interactions (Martin \& Nakayama, 2010). Two major techniques for managing the anxiety reduction were uncovered in the findings; one is to improve students' language skills. The other is to familiarize them with host cultural norms, values, and practices.

An international student told me that she wanted to hang out with American students. But it was not that easy because sometimes she found it difficult to participate in their social activities and make them see her as part of that cultural group. For example, her American friend invited her to a party two weeks ago and it was not a pleasant experience. She said all the present partyers were talking about sex and sports, and they drank excessively. She felt embarrassed because no one seemed interested in talking to her. Some of the people whom she talked walked away from her quickly when they realized she did not carry the conversation very well. She said:

"I still want to be part of them. I just had a bit of hard time getting used to the activities that they find fun and entertaining outside the class. I think if I stay here for a longer time, it might be easier for me."

Her last statement is symbolic of the common struggle that the cultural other experiences when trying to engage a productive dialogue and interaction with the host cultural group (Martin \& Nakayama, 2010). When situated within a particular context where one's cultural values and beliefs were challenged, it is common for that person to feel left out (Martin \& Nakayama, 2010). Newcomers should act motivated and excited when striving to have a conversation with the members of the host cultural group (Martin \& Nakayama, 2010). International students easily harbor the misperception that the domestic students' apathetic attitude towards them means they do not like them because they are foreign. International students need to avoid such negative thought and come to the understanding that domestic students might not be that assertive and 
comfortable when interacting with someone from a different culture. It is not they do not like you, it is more likely they do not know you.

Following this line of thinking, international students need to be forward and enthusiastic in learning about the host culture and educating the host about their cultural values and perceptions. It is through this vigorous exchange process where the newcomers try to obtain an in-depth understanding about the cultural values supported by the host, and actively share the cultural differences between each other, a productive and respectful learning and teaching environment can be fostered.

\section{Discussion \& Conclusion}

The present study uncovered and analyzed the challenges in managing diverse cultural voices in a multicultural communication setting. The analysis revealed a variety of critical issues in a diverse teaching and learning environment. The domestic and international students' different ways of addressing their professors, in-class behaviors, approaches to creative class and social activities underline the crucial roles that the cultural differences play in shaping the experiences and outcomes of teaching and learning. Thus, it is important to develop a feasible strategy that can effectively reduce the misunderstandings brought forth by the cultural differences. In particular, the current study is focused on investigating how the international faculty members handle the different cultural needs and perspectives. So the situation became more challenging because the professors themselves were constantly placed in a third cultural context where they had to struggle with the influence that their own cultural identities cast on making the decisions and ways of interacting with both the international and domestic students.

The analysis also implied that the search for a method or one course policy is not going to provide a real solution to the problem. Rather, the professors should encourage students to think in each other's positions. They need to be culturally sensitive and strive to bridge the cultural gaps among students by providing both opportunities and spaces for them to develop meaningful and constructive cross-cultural dialogues. This is the key theoretical implication advanced by the findings.

It is through an active exchange of each other's views on different issues, a positive integration of diverse cultural voices could likely be realized. Such approach is more realistic, doable, and acceptable than forcing cultural assimilation onto either the newcomers or the hosts who tend to have a difficult time understanding the newcomers. The development of such a connection and interaction through active cross-cultural dialogues would be more effective, long- 
lasting, and productive than having a particular course policy to cope with, manage, and explain various issues central to the experiences with teaching and learning in a multicultural environment.

\section{Limitations and Suggestions for Future Studies}

The major research methods that were used for this project were semi-structured interviews and non-participation observations. The present study could have been more substantiated if other methods of data collection were incorporated. For instance, some online interactive platforms could have been explored as a possible way to learn how students reflected on their learning experiences in a multicultural environment. It is possible that some students did not share their true feelings with me because the interview was conducted on campus in a faceto-face style. If I examined some students-run online posting bulletins or chatrooms analyzing the comments about their classes, it might have provided me with different sets of data and showed different interpretations because those virtual spaces protect anonymity.

Finally, the university where the data were collected did not represent all types of universities in the United States. Institutions such as private colleges or universities located in metropolitan areas may enroll students of the immensely diverse cultural backgrounds and national origins, which in so far could result in different responses and challenge the current findings. The future inquiry should continue this line of exploration and study how different communication forums and institutional spaces shape and form the complex interactions among students and faculty members.

\section{References}

Alberts, H. C., \& Hazen, H. D. (2010). Classroom incivilities: The challenge of interactions between college students and instructors in the US. Journal of Geography in Higher Education, 34 (3), 439-462. Doi: 10.1080/03098260903502679

Barlatt, G. R. (2000). Developmental education and teaching processes: An exploration of ethical dilemmas (Doctoral dissertation). Retrieved from Community College Journal of Research and Practice. (University Microfilms No. 99-73933)

Begley, T. P., \& Stefkovich, A. J. (2004). Introduction: Education, ethics, and the "cult of efficiency": Implications for values and leadership. Journal of Educational Administration, 42 (2), 132-136. Doi: 10.1108/09578230410525568

Cowley, P., \& Hanna, B. E. (2005). Cross-cultural skills - crossing the disciplinary divide. Language \& Communication, 25 (1), 1-17. Doi: 10.1016/j.langcom.2004.05.002

Ersanilli, E., \& Koopmans, R. (2010). Rewarding integration? Citizenship regulations and the socio-cultural integration of immigrants in the Netherlands, France and Germany. Journal of Ethnic and Migration Studies, 36 (5), 773-791. Doi: $\underline{10.1080 / 13691831003764318}$

Gee, J. P. (2014). An introduction to discourse analysis: Theory and method. London and New 
York: Routledge. Doi: 10.4324/9781315819679

Gutierrez, K. J., \& Preston, C. G. (2004) Re-examining race-based admissions processes of American institutions of higher education using multi-dimensional ethical perspectives. Journal of Educational Administration, 42 (2), 236 - 248. Doi: $\underline{10.1108 / 09578230410525621}$

Jonsson, P. (2001, November 6). When teachers' ethics come into question. Retrieved from https://www.csmonitor.com/2001/1106/p11s1-lekt.html

Ketko, T. (2017). Teachers in multi-cultural societies: Excellence and leadership. International Journal of Learning, Teaching and Educational Research, 16 (4), 54-66.

Kim, D., Wendel, L. W., \& Twombly, S. (2011). International faculty: Experiences of academic life and productivity in U.S. universities. The Journal of Higher Education, 82 (6), 720-747. Doi: 10.1353/ihe.2011.0038

Leonard, P., \& Leonard, L. (2006). Teachers and tolerance: Discriminating diversity dispositions. Regional Educational Laboratory: Brown University, 42, 30-61. Doi: $\underline{10.1080 / 08878730609555392}$

Liu, M. (2009). The intrapersonal and interpersonal effects of anger on negotiation strategies: A cross-cultural investigation. Human Communication Research, 35 (1), 148-169. Doi: $10.1111 / \mathrm{j} .1468-2958.2008 .01342 . \mathrm{x}$

Martin, J. N., \& Nakayama, T. K. (2010). Intercultural communication in contexts. Boston, MA: McGraw Hill.

Moffat, W. W. (1995). The other side of the Asian American success story. Hoboken, NJ: Wiley.

Murphy, J. (2005). Connecting teacher leadership and school improvement. Thousand Oaks, CA: Corwin Press.

Rogoff, B. (2003). The cultural nature of human development. New York, NY: Oxford University Press. Doi: 10.1111/j.1548-1352.2011.01177.x

Tompson, H. B., \& Tompson, G. H. (2010). International perspective: Confronting diversity issues in the classroom with strategies to improve satisfaction and retention of international students. Journal of Education for Business, 72 (1), 53-57. Doi: $10.1080 / 08832323.1996 .10116826$

Uskul, A. K., Lalonde, R. N., \& Cheng, L. (2007). Views on interracial dating among Chinese and European Canadians: The roles of culture, gender, and mainstream cultural identity. Journal of Social and Personal Relationships, 24 (6), 891-911. Doi: $10.1177 / 0265407507084189$

Zhong, B. (2008). Thinking along the cultural line: A cross-cultural inquiry of ethical decision making among U.S. and Chinese journalism students. Journalism $\mathcal{E}$ Mass Communication Educator, 63 (2), 110-126. Doi: $\underline{10.1177 / 107769580806300202}$ 